\title{
Responsabilidad social y bienestar de la persona mayor
}

\author{
Lourdes Osorio Bayter \\ Francisco Salinas Ramos \\ Margot Cajigas Romero
}

RESUMEN: Este artículo muestra algunos de los resultados del estudio realizado entre el 2012 y 2015 en dos contextos, Colombia y España, cuyo objetivo fue conocer la realidad social de un segmento de mercado en crecimiento y la importancia de las políticas gubernamentales y sociales vigentes para la protección y calidad de vida de la población adulta mayor. Se definen las variables, estructuran y aplican tres encuestas estructuradas y un cuestionario, resaltando las residencias como punto de partida y los diferentes públicos involucrados: adultos mayores, familiares, directivos de centros residenciales y expertos en el tema, compilando información primaria y secundaria referente al hogar/residencia de la persona mayor y las políticas de bienestar en protección, responsabilidad social y centros asistenciales. La salud en la persona se deteriora con el envejecimiento, requiriendo atención especial; siendo la economía social y los centros de promoción, los llamados a tomar cartas en el asunto con mayor inclusión, teniendo en cuenta la trihélice o cuadrihélice social: academia (estudiantes y profesores), empresa social, gobierno (local y nacional) y comunidad (voluntarios). Es necesario coordinar y promover iniciativas de cooperación nacional e internacional, que creen vínculos con diferentes stakeholders, logrando satisfacer necesidades y deseos, así como la calidad y pertinencia del servicio percibido por el adulto mayor, tanto en las residencias como en el entorno externo donde residen.

PALABRAS CLAVE: Adulto mayor, Bienestar social, Economía social, Responsabilidad social, Tercer sector.

CLAVES ECONLIT: J14, I31, P46, M14.

Cómo citar este artículo / How to cite this article: OSORIO, L., SALINAS, F. \& CAJIGAS, M. (2018): "Responsabilidad social y bienestar de la persona mayor", CIRIEC-España, Revista de Economía Pública, Social y Cooperativa, 92, 223-252.

Correspondencia: Lourdes Osorio Bayter, Profesora Administración de Empresas Universidad Autónoma de Occidente - Santiago de Cali - Colombia. Grupo de Investigación en Ciencia Administrativas- GICAD, leosorio@uao.edu.co.

Francisco Salinas Ramos, Profesor Universidad Católica de Ávila - España. Director de la Cátedra Economía Social, Cooperativismo y Dependencia, francisco.salinas@ucavila.es

Margot Cajigas Romero, Profesora Contaduría Pública. Universidad Autónoma de Occidente Santiago de Cali - Colombia. Grupo de Investigación en Economía y Desarrollo- GIED, Aspirante a Doctor en Ciencias Económicas y Empresariales de la Universidad de Granada, España, mcajigas@uao.edu.co 


\section{EXPANDED ABSTRACT}

\section{Social responsibility and welfare of elderly people}

In recent years, there has been a change in the topic of protection of the elderly in the world, due to the demographic transition process involving growth in the aging of the population and the foreseeable consequences. This is the reason why there has been a need for a common frame of reference for the welfare, protection and promotion of the rights of the elderly, including the contribution they can make to society, as well as the products and services that they perceive according to the requirements they demand.

This article shares some results of the study*, carried out between 2012 and 2015 in two contexts, Colombia and Spain, whose objective was to understand the social reality of a growing market segment and the importance of current government and social policies for the protection and quality of life in senior citizen population.

Health deteriorates generally as it advances in age, requiring special attention in the medium and long term, transposed into greater demand for services for the older person. Social economy companies are called to take action on the matter, considering, in truth, of components of the social quadrihelix, composed of: a) academia, through the approach of new professional skills, the exchange of experiences and the promotion of good practices, in addition to research and innovation for the elderly, b) the company, generating or providing appropriate services and products for this population, c) local, regional and national government through the enactment and implementation of the national policy of aging, seeking the protection and defense of the rights of the elderly, and d) the community, through volunteering and the inclusion of the person in conditions of social vulnerability. Thus, the four fronts, imply the commitment that both the citizen and the institutions have to society, in a common work under the same purpose, make visible the degree of corporate and institutional social responsibility and the implementation in benefit of appropriately intervening the situation of old age of population, coordinating and promoting national and international cooperation initiatives that create links with different stakeholders, in order to meet the needs, desires, expectations and tastes, through the quality and relevance of the service perceived by the older person, both in the residences where they live, the products they buy and consume, inside and outside the environment where they reside.

* "Variables of Influence in Preference and Brand Loyalty, in Residences of Older Adults. A comparative social analysis between ÁvilaMadrid (Spain) and Santiago de Cali (Colombia)". Research report. 2017. 
The advances of science in recent years has been vertiginous, in a more significant way in medicine and in the new technologies applied to medical science in the pharmacological field, favouring longevity with quality life for the elderly, providing them with the opportunity for more autonomy, physical and mental activity. At the same time, it means that companies and institutions must offer new and better services in accordance with the expectations and needs, not only of the elderly, but also of the family members and administrative staff of the home/residence who need to improve the well-being of the person in charge of, allowing the user to make their own decisions of where to live, what products to consume, which brands and characteristics according to benefits they perceive and require.

This is how, from the theoretical review on key conceptions of the elderly**, the demographic trends, the institutional framework of welfare policies in protection and social responsibility that affect the population of the elderly and that could influence health, housing, security and pensions, the variables to be taken into account were defined and three structured surveys and a questionnaire were designed to obtain primary information, highlighting the residences as a starting point and the public involved: seniors, relatives, directors of residential centers and subject matter experts. Allowing to contextualize "in a general way" the social welfare, the socioeconomic situation of the elderly population and the social policies that shelter it, as well as the business environment considered a challenge in the population aging process, which goes from managing human talent as a strategic asset in a competitive society until defining and implementing inclusive public policies. Reaching some theories and approaches of entrepreneurship social responsibility and the relationship between business / senior citizens, starting from the liberal relation to the approach of social institutions and thus get to relate some considerations of the residential environment (Colombia-Spain) and quality components of life as a foundation of the social welfare of the elderly as a being of multiple and interdependent needs.

Finally, the study shows how, in Spain, in contrast to Colombia, interventions for the benefit of the elderly are notable, from the relationship with workers, volunteers and families. Meanwhile, corporate relations in social management, cooperation and solidarity, are found to be more visible in Spain as a comprehensive strategy and social content, however in both contexts there are gaps in innovation, in processes and products for the activity and physical mobility of this population. In same way, they are also working on the relationship: social responsibility / innovation. In Colombia, some progress has been made, but there is still a lack of promotion, articulation and initiatives of internal and external social responsibility, since there are no clear guidelines in a social responsibility

\footnotetext{
** In this article, the terms "elderly", "older person" or "senior citizen" are used interchangeably. Is the person who is 65 and over or 60 years or older, conventionally accepted age in one and another country (Spain and Colombia). As well as, "Social Responsibility", refers to the commitment or obligation of the members of a society, either as individuals or as members of a group, both among themselves and for society as a whole and the environment.
} 
management system that supports initiatives and proposals to manage participation or links with other entities of different sectors. However, in both contexts, it is necessary to coordinate and promote national and international cooperation, which allow the link with different stakeholders, in order to achieve the satisfaction of needs and desires, as well as the quality and relevance of perceived service by the older adult, in the residences and in the external environment where they reside.

KEYWORDS: Older Adults, elderly, social welfare, social economy, social responsibility. 


\section{Introducción'1}

En los últimos diez años, se presenta un cambio en el tema de la protección y amparo de la persona Adulto Mayor en el mundo, gracias a la divulgación en congresos Iberoamericanos y mundiales, la comunidad ha entendido la complejidad y rapidez del fenómeno del envejecimiento en la población mundial y la necesidad de que exista un marco de referencia común para el bienestar, la protección y promoción de los derechos de la persona mayor, incluida la contribución que ellas pueden aportar a la sociedad.

Según los estudios demográficos de Naciones Unidas, "el envejecimiento de la población está a punto de convertirse en una de las transformaciones sociales más significativas del siglo XXI", así lo indica el informe «Perspectivas de la Población Mundial», la población mayor crece más rápido que la joven. Se espera que el número de personas mayores de 60 años se duplique para 2050 y triplique para el año 2100; pasando de 962 millones en 2017 a 2100 millones en 2050. El mismo informe manifiesta que traerá "consecuencias para casi todos los sectores de la sociedad, entre ellos, el mercado laboral y financiero y la demanda de bienes y servicios (viviendas, transportes, protección social...), así como para la estructura familiar y los lazos intergeneracionales". (ONU, 2017).

La salud de la población adulto mayor, generalmente se deteriora con la edad, lo que se traduce en una mayor demanda de atención a mediano y largo plazo. Haciendo frente a esta realidad mundial, Naciones Unidas en el contexto de la Segunda Asamblea Mundial sobre Envejecimiento, celebrada en Madrid en abril de 2002, se aprobó el Plan de Acción Internacional y Declaración Política sobre el envejecimiento (MIPAA, siglas en inglés), acordándose también que, para septiembre 2002, todos los Estados miembros de la UE reunidos en Berlín se ratificaría el MIPAA. Todos los miembros, se comprometieron a promover el envejecimiento activo ${ }^{2}$, integrando los derechos y necesidades de las personas mayores, en su economía nacional y en las políticas sociales, promoviendo una sociedad para todas las edades.

Por su parte, Colombia, cuenta con una Política nacional de envejecimiento y vejez, la cual está dirigida a toda la población residente en el país, en especial, a las personas mayores de 60 años, que se encuentran en condiciones de vulnerabilidad social, económica y de género, respaldada por Ley

1.- Este artículo muestra algunos de los resultados del estudio "Variables de Influencia en la Preferencia y Lealtad de Marca, en Residencias de Adultos Mayores. Un Análisis Social Comparativo entre Ávila-Madrid (España) y Santiago de Cali (Colombia)". Informe de investigación. 2017.

2.- La Organización Mundial de la Salud define el envejecimiento activo como el proceso en que se optimizan las oportunidades de salud, participación y seguridad a fin de mejorar la calidad de vida de las personas a medida que envejecen. El envejecimiento activo permite que las personas realicen su potencial de bienestar físico, social y se centra en las personas mayores y en la importancia de dar una imagen pública positiva de este colectivo. 
1251 de 27 de noviembre de 2008 (Congreso de la Republica, 2008), norma para procurar la protección, la promoción y la defensa de los derechos de los adultos mayores. En los últimos años la protección de los derechos a los adultos mayores se ha convertido en una política de Estado, debido al creciente registro de vulneración de los derechos de los mismos; y tiene como propósito visibilizar e intervenir la situación del envejecimiento y la vejez en el periodo 2007-2019. (Osorio \& Salinas, 2016).

Por lo tanto, surgen algunos interrogantes sobre el adulto mayor y la responsabilidad social, como: ¿la sociedad civil y el medio empresarial, qué acciones o estrategias han tomado para hacer frente al envejecimiento poblacional?; ¿quiénes lo proyectan para el entorno de mercado y el sector académico-investigativo como una gran oportunidad?; ¿se tiene en cuenta el comportamiento de preferencias frente a los productos y servicios que adquieren y consumen en el entorno residencial de las adultos mayores?, y, el marco institucional que acoge las políticas sociales referente a la población adulta mayor en Colombia y España, ¿cómo las afecta e impacta?. Partiendo de estos interrogantes, se valida el objetivo de estudio, el cual buscó conocer la realidad social de un segmento de mercado en crecimiento, y la importancia de las políticas gubernamentales y sociales vigentes para la protección y calidad de vida de la población, adulto mayor en dos contextos, Colombia y España; tema de interés, tanto para los profesionales de la gestión y mercadeo, como de los sociólogos, psicólogos, trabajadores sociales al permitir comprender el comportamiento de los adultos mayores, ante las expectativas que el mercado espera satisfacer según necesidades, y así, diseñar ofertas de valor agregado, para atender este segmento creciente a nivel mundial.

Por tanto, es relevante incorporar la Responsabilidad Social (RS), la cual implica el compromiso que tiene todo ciudadano y las organizaciones e instituciones (públicas, privadas, sociales y empresariales) de contribuir al aumento de la calidad de vida y al cuidado del medio ambiente de la sociedad tanto a nivel local como global (Salinas, Osorio \& Albarrán, 2011). Los términos Responsabilidad Social de las Empresas (RSE) y Responsabilidad Social Corporativa RSC), se centran en promover buenas prácticas organizacionales para dar cuenta de su compromiso por el bienestar del entorno y la sociedad, llámese públicos internos o externos, y el adecuado uso de los recursos medio ambientales (Rodríguez \& Moyano, 2015). Para efecto de este documento, se denota Responsabilidad Social (R.S.), definida en el 2001 en Bruselas por la Comisión de las Comunidades Europeas (Comisión Europea, 2011, 4) como: "la integración voluntaria, por parte de las organizaciones, de las preocupaciones sociales y medioambientales en sus operaciones comerciales, sociales y sus relaciones con sus interlocutores". En 2011 la misma Comisión propone una nueva definición para asumir la RSE, en la cual dice: "las empresas deben aplicar, en estrecha colaboración con las partes interesadas, un proceso destinado a integrar las preocupaciones sociales, medioambientales y éticas, el respeto de los derechos humanos y las preocupaciones de los consumidores en sus operaciones empresariales y su estrategia básica, a fin de: maximizar la creación de valor compartido para sus propietarios/accionistas y para las demás partes interesadas y la sociedad en sentido amplio; e identificar, prevenir y atenuar sus posibles consecuencias adversas." $(2011,7)$. Además, menciona que: "Algunos tipos de empresas, como las cooperativas, las mutuas y las empresas familiares, tienen estructuras de propiedad y de gobernanza que pueden ser especialmente propicias para una gestión empresarial responsable" (2011, 8; Jorge \& Albarrán, 2013). 
A partir de la revisión teórica sobre las concepciones claves del adulto mayor y la responsabilidad social; se definieron las variables y se diseñaron tres encuestas estructuradas y un cuestionario, para obtener información primaria de una muestra de adultos mayores, familiares, directivos de centros residenciales y expertos en el tema según el contexto explicado en la metodología. Lo cual permitió contextualizar y establecer la situación socioeconómica, el entorno empresarial, residencial y los componentes de las políticas gubernamentales para la protección y calidad de vida del adulto mayor ${ }^{3}$.

Finalmente, el estudio muestra cómo, en España a diferencia de Colombia, las intervenciones en beneficio del adulto mayor, es notable, desde la relación con los trabajadores, los voluntarios y las familias, se cuenta con programas a favor del adulto mayor. Igualmente se encuentran relaciones corporativas en la gestión social y cooperación y solidaridad. Son visibles las estrategias integrales y de contenido social, sin embargo, existen carencias en innovación en procesos y productos propios para la actividad y movilidad física del adulto mayor. Se está trabajando en la relación RS e innovación. En Colombia, se ha avanzado algo, pero aún falta promoción, articulación e iniciativas de R.S. interna y externa, puesto que no existen lineamientos claros en un sistema de gestión de R.S. que apoye iniciativas y propuestas para gestionar la participación o vínculos con otras entidades de diferentes sectores. Sin embargo, en ambos contextos, se requiere coordinar y promover iniciativas de cooperación nacional e internacional, que permitan el vínculo con diferentes stakeholders, con el fin de lograr la satisfacción de las necesidades y deseos, así como, la calidad y pertinencia del servicio percibido por el adulto mayor, tanto en las residencias como en el entorno externo donde residen.

\section{Metodología}

Para lograr el alcance de la investigación, fue necesario acudir a fuentes secundarias, que mostraron las tendencias demográficas, el marco institucional de las políticas sociales en Colombia y España que inciden e impactan a la población del adulto mayor, y que pudiesen influir (positiva o negativamente) en la calidad de vida (salud, vivienda, pensiones), con especial énfasis en las residencias, identificando variables sociales y el contexto político. El trabajo fue realizado en varias etapas de investigación de tipo documental, exploratoria y descriptiva.

Por consiguiente, se ubica un segmento específico de la persona mayor, resultando las residencias como punto de partida y los diferentes públicos involucrados. Se estructuraron cuatro instrumen-

3.- En este artículo se utilizará indistintamente los términos "persona mayor" o "adulto mayor". El primero utilizado en España y el segundo en Colombia. Es la persona que tiene 65 y más años o 60 años o más, edad convencionalmente aceptada en uno y otro país.

"Responsabilidad Social", nos referimos al compromiso u obligación de los miembros de una sociedad, ya sea como individuos o como miembros de algún grupo, tanto entre sí como para la sociedad en su conjunto y el medio ambiente. 
tos de recolección, para compilar la información primaria, de acuerdo a los objetivos propuestos. Luego de realizar las pruebas e identificaciones de la población, se procedió a efectuar la fase exploratoria con el trabajo de campo teniendo en cuenta los elementos descritos en la tabla 1, tanto del tamaño de muestra para cada público como los instrumentos utilizados en cada contexto según interés. Los resultados cualitativos, arrojaron aspectos del comportamiento humano como: motivaciones, actitudes, creencias, satisfacción y poder demandado entre otros; mientras que los resultados cuantitativos indican: aspectos medibles como el consumo, lugares de compra, rotación de personal especializado y administrativo en las residencias y la toma de decisiones. Logrando, describir la realidad sobre el bienestar en el entorno residencial del adulto mayor.

En cuanto a los instrumentos utilizados, las encuestas fueron diseñadas de tal manera que se minimizará el margen de error, convirtiéndose en un instrumento de recolección de información confiable para la medición de los resultados. El cuestionario fue un formato estructurado para cumplir el objetivo de cada público a analizar. Entre tanto, la entrevista en profundidad fue utilizada para explorar las razones implícitas en las actitudes y comportamientos frente al objeto analizado. El temario fue flexible, sin forzar respuestas, procurando de esta manera que los entrevistados pudiesen expresar cómodamente sus actitudes, intereses y opiniones. Una vez recopilada la información se tabularon los datos y se analizaron los resultados de los cuatro grupos de interés.

Las empresas del sector social (España) y solidario (Colombia), representan empresas privadas y no públicas o del Estado. Por tanto, para Colombia (Cali) como para España (Madrid y Ávila), se consideraron residencias privadas del ámbito social/solidario (no mercantil).

En Colombia se tratan en su mayoría de fundaciones, lo que quiere decir, que son empresas privadas del sector solidario, entre tanto las de España, hacen parte de la Federación de Residencias y Servicios de Atención a Mayores -Sector Solidario- (LARES), de ámbito estatal, son de carácter privado y del sector social. Para ambos casos se tuvieron en cuenta las características, como pertenecer a un estrato socioeconómico alto o medio alto -en Ávila medio bajo- (Caso España) y estratos 4, 5 y 6 (caso Colombia), quedando la categoría en la escala social, similares. En cuanto a España y teniendo en cuenta las pautas del cálculo de la muestra aplicada para Cali, se realiza un muestreo de tipo no probabilístico por conveniencia o de juicio. El resultado se adecuó y adaptó al trabajo de campo de Madrid y Ávila. En total la muestra es de 12 residencias, que están en dos territorios diferentes. Por un lado, la Comunidad Autónoma de Madrid y por otro, a la provincia de Ávila, que es parte de la Comunidad Autónoma de Castilla y León. Conviene destacar que la muestra no es del universo de residencias (públicas y privadas) que existen en estos territorios, sino, sólo de las residencias o centros asistenciales/residenciales que pertenecen al sector solidario, concretamente a LARES Federación. 


\section{Tabla 1. Trabajo de campo para Cali - Colombia, Madrid y Ávila - España}

\begin{tabular}{|c|c|c|c|c|c|}
\hline $\begin{array}{l}\text { Grupo de interés } \\
\text { objetivo }\end{array}$ & Universo & $\begin{array}{l}\text { Tamaño de } \\
\text { muestra }\end{array}$ & $\begin{array}{l}\text { Aplicación del } \\
\text { instrumento }\end{array}$ & $\begin{array}{l}\text { Características de la muestra y } \\
\text { objetivo }\end{array}$ & Instrumento \\
\hline CALI - COLOMBIA & 40 & 28 & & $\begin{array}{l}\text { Se rastrea y predefine el universo } \\
\text { y se calcula la población, se veri- } \\
\text { fica el filtro de la muestra aleato- } \\
\text { riamente y a juicio para estratos } 4 \text {, } \\
5 \text { y } 6 \text {. } \\
\text { Hogares geriátricos de carácter } \\
\text { privado y del sector social (Funda- } \\
\text { ciones). }\end{array}$ & $\begin{array}{l}\text { La encuesta se apli- } \\
\text { ca según disponibili- } \\
\text { dad de la persona y } \\
\text { a criterio de directi- } \\
\text { vos. }\end{array}$ \\
\hline $\begin{array}{l}\text { Directivos Hogares de } \\
\text { Adultos mayores }\end{array}$ & 40 & 28 & 24 & $\begin{array}{l}\text { Se analiza la estructura adminis- } \\
\text { trativa y percepción de los admi- } \\
\text { nistradores }\end{array}$ & $\begin{array}{l}\text { Encuesta. Formato } \\
\text { estructurado y de } \\
\text { objetivo preciso. }\end{array}$ \\
\hline $\begin{array}{l}\text { Usuarios adultos ma- } \\
\text { yores ubicados en ho- } \\
\text { gares }\end{array}$ & 40 & 28 & 60 & $\begin{array}{l}\text { Determinar aspectos del compor- } \\
\text { tamiento humano en la adultez. } \\
\text { Además de aspectos medibles de } \\
\text { consumo y necesidades }\end{array}$ & $\begin{array}{l}\text { Encuesta. Formato } \\
\text { estructurado y de } \\
\text { objetivo preciso. }\end{array}$ \\
\hline $\begin{array}{l}\text { Familiares de los } \\
\text { adultos mayores }\end{array}$ & 40 & 28 & 18 & $\begin{array}{l}\text { Analizar percepción y comporta- } \\
\text { miento del familiar. }\end{array}$ & $\begin{array}{l}\text { Encuesta. Formato } \\
\text { estructurado y de } \\
\text { objetivo preciso. }\end{array}$ \\
\hline $\begin{array}{l}\text { Experto en Comuni- } \\
\text { cación y publicidad y } \\
\text { otros medios }\end{array}$ & & & 2 & $\begin{array}{l}\text { Explorar las razones implícitas en } \\
\text { las actitudes y comportamiento } \\
\text { frente al adulto mayor. }\end{array}$ & $\begin{array}{l}\text { Entrevista a profun- } \\
\text { didad }\end{array}$ \\
\hline $\begin{array}{l}\text { MADRID Y ÁVILA - } \\
\text { ESPAÑA }\end{array}$ & $\begin{array}{l}38 \text { Madrid } \\
8 \text { Ávila }\end{array}$ & $\begin{array}{l}8 \text { Madrid ( } 5 \text { ur- } \\
\text { banas y } 3 \text { rura- } \\
\text { les) } \\
4 \text { Ávila ( } 3 \text { urba- } \\
\text { nas y } 1 \text { rural) }\end{array}$ & & $\begin{array}{l}\text { Se define el universo: Residencias } \\
\text { de la Federación (LARES). Son } \\
\text { carácter privado y del sector } \\
\text { social. Estrato alto o medio alto. }\end{array}$ & $\begin{array}{l}\text { Muestra residencial } \\
\text { es escogida aleato- } \\
\text { riamente. El instru- } \\
\text { mento se aplica a } \\
\text { criterio de directivos. }\end{array}$ \\
\hline $\begin{array}{l}\text { Directivos Hogares de } \\
\text { residencias }\end{array}$ & $\begin{array}{l}38 \text { Madrid } \\
8 \text { Ávila }\end{array}$ & & $\begin{array}{l}\text { Madrid } 8 \\
\text { Ávila } 4\end{array}$ & $\begin{array}{l}\text { Se analiza la estructura adminis- } \\
\text { trativa y percepción de los admi- } \\
\text { nistradores. }\end{array}$ & $\begin{array}{l}\text { Encuesta. Formato } \\
\text { estructurado y de } \\
\text { objetivo preciso. }\end{array}$ \\
\hline $\begin{array}{l}\text { Usuarios adultos ma- } \\
\text { yores ubicados en las } \\
\text { residencias }\end{array}$ & $\begin{array}{l}38 \text { Madrid } \\
8 \text { Ávila }\end{array}$ & & $\begin{array}{l}\text { Madrid } 4 \\
\text { Ávila } 4\end{array}$ & $\begin{array}{l}\text { De } 32 \text { personas mayores se esco- } \\
\text { gen } 4 \text {. De } 16 \text { personas se escogen } \\
4 \text { ( } 2 \text { hombres y } 2 \text { mujeres en cada } \\
\text { residencia). Determinar aspectos } \\
\text { del comportamiento humano en la } \\
\text { adultez. Además de aspectos me- } \\
\text { dibles de consumo y necesida- } \\
\text { des. }\end{array}$ & $\begin{array}{l}\text { Encuesta. Formato } \\
\text { estructurado y de } \\
\text { objetivo preciso. }\end{array}$ \\
\hline $\begin{array}{l}\text { Familiares de los } \\
\text { adultos mayores }\end{array}$ & $\begin{array}{l}38 \text { Madrid } \\
8 \text { Ávila }\end{array}$ & & $\begin{array}{l}\text { Madrid } 6 \\
\text { Ávila } 6\end{array}$ & $\begin{array}{l}\text { Analizar percepción y comporta- } \\
\text { miento del familiar. }\end{array}$ & $\begin{array}{l}\text { Encuesta. Formato } \\
\text { estructurado y de } \\
\text { objetivo preciso. }\end{array}$ \\
\hline
\end{tabular}

FUENTE: Elaboración propia a partir de la investigación (2017). 


\section{El bienestar social del adulto mayor. Contextualización}

El proceso de envejecimiento de la población es evidente, las personas de 60 años y más, superan a los menores de 14 años, así lo demuestra las cifras históricas y las proyecciones. En 1950 aumentó en 20 años la esperanza de vida en el mundo y se espera que en el futuro el incremento sea de más de 30 años. En el 2005 ya existían más de 75'000.000 de personas mayores de 80 años en el planeta y para el 2050 se esperan más de 330'000.000 mayores de 80 años viviendo en el mundo (Banco Mundial, 2015).

La esperanza de vida se ha incrementado en todas las esferas del planeta En Estados Unidos y Japón, la esperanza de vida está por encima de los 80 años. Por su parte en América Latina el envejecimiento, es uno de los retos demográficos a los que se enfrenta, en tanto ejercerá una presión en los sistemas de seguridad social, los sistemas de asistencia sanitaria, la atención y cuidado de las personas mayores. El desafío se centra en cómo enfrentar este reto a través de la definición de estrategias claras que garanticen un nivel de vida digno, para las personas mayores, permitiéndoles favorecerse del bienestar económico de su país y participar activamente en la vida pública, social y cultural (Miquel, 2015). Para el caso de España el envejecimiento de su población se debe, entre otros motivos, a la baja tasa de natalidad y al aumento de la esperanza de vida, la cual se encuentra en 86 años para las mujeres y 82 para los hombres; las personas de 100 años y más va aumentando significativamente. Y para el caso de Colombia, mujeres de 78 y hombres 71 años (Banco Mundial, 2015).

Para hacer frente a esta evidente situación en América Latina y el Caribe se ha diseñado y puesto en marcha iniciativas diversas, la mayoría de ella al albur de las orientaciones de Naciones Unidas. Los dos siguientes párrafos referencian algunas de ellas (Huenchuan, 2004; 2010) "...a fines de la década de los ochenta se incorporaron medidas específicas en favor de las Personas Mayores en el Protocolo Adicional a la Convención Americana sobre Derechos Humanos de Derechos Económicos, Sociales y Culturales, Protocolo de San Salvador, siendo a la fecha el único instrumento vinculante para los países que lo han ratificado. Otro instrumento de importancia para los países de la región es la Estrategia Regional de Implementación para la región del Plan de Acción Internacional sobre el Envejecimiento, adoptada en noviembre de 2003 en el cual se dieron las bases para la acción en materia de atención a la vejez para los próximos años y constituye el primer instrumento regional de este carácter".

Ya para la década de los noventa "varios países latinos iniciaron el diseño y/o implementación de políticas expresamente dirigidas a las personas mayores. Algunos de ellos promulgaron leyes especiales y las reformas constitucionales en curso permitieron, en algunos casos, incorporar asuntos específicos relacionados con los derechos de las personas mayores. Hitos impulsores de estos procesos 
han sido, principalmente, la adopción de los Principios de las Naciones Unidas, el Año Internacional de las Personas de Edad y, recientemente, la Segunda Asamblea Mundial sobre el Envejecimiento realizada en Madrid en el año 2002" (Huenchuan, 2004; 2010).

El proceso de transición demográfica que ha tenido lugar en Colombia y España en las últimas décadas ha modificado el perfil poblacional de estos países. La heterogeneidad en este aspecto implica diferencias en la disminución del crecimiento de la población y el envejecimiento de las estructuras de edad, que a su vez inciden en el tipo y la magnitud de los problemas que estos países deberán encarar en las próximas décadas. El envejecimiento y sus consecuencias es un proceso ineludible pero previsible, cuantificable y, por lo tanto, manejable, si lo tenemos en cuenta desde ahora. Los indicadores de transición demográfica muestran que la población colombiana es 'madura', según el índice de Friz 4 .

Entre tanto en España, el fenómeno del envejecimiento se observa especialmente acelerado, como consecuencia de una mayor longevidad, ya que en menos de 30 años se ha duplicado el número de personas mayores de 65 años. Este proceso se ve acentuado por la baja tasa de natalidad que se viene registrando desde hace algunas décadas. Esta reducción se registra en España aproximadamente desde mediados de los años 70 . En 1975, el promedio de hijos era de casi 3 por mujer en edad fértil, mientras que actualmente apenas es de 1,2 hijos. Según datos del Padrón Continuo (Instituto Nacional de Estadística -INE- a 1 de enero de 2016 hay 8.657 .705 personas mayores (65 y más años), representando un $18,4 \%$ del total de la población (46.557.008), de igual manera las proyecciones del INE, en 2066 habrá más de 14 millones de personas mayores, 34,6\% del total de la población que alcanzará los 41.068.643 habitantes. (Abellán, Ayala, \& Pujol, (2017). Por su parte en el contexto colombiano, "la población de 60 años o más tiene tasas de crecimiento superiores al crecimiento de la población total, entre 1985 y el año 2013, la población total de 60 años o más pasó de 2.143 .109 a 3.815 .453 en el 2005 y para el 2010 se proyectó en 4.473 .447 de personas mayores, con un ritmo de crecimiento del $3.18 \%$ promedio anual en ese periodo. Para el 2015 se proyecta un crecimiento de la población mayor en un 3.51\% y del 3.76\% para el 2020" (Ministerio de Salud y Protección Social, 2013).

\subsection{Situación socioeconómica de la población adulto mayor}

La importancia que va tomando el incremento del envejecimiento poblacional sumado a las condiciones de vida de las personas mayores, cabe precisar sobre la gerontología social, la cual se encarga de estudiar a la persona como un ser integral, teniendo en cuenta el entorno social y familiar donde vive, así como la situación socioeconómica. De acuerdo a un estudio sobre los adultos mayores, la

4.- El índice de Friz. Técnica aplicada al envejecimiento demográfico. Representa el porcentaje de población por rangos: de menos de 20 años, grupo de población entre los 30 y los 49 años y se toma como base 100 (por cada 100 personas). Cuando éste índice supera el valor de 160 se considera que la población estudiada es una población joven, si el índice es entre 60 y 160 es madura, mientras que si resulta inferior a 60 se considera una población envejecida. 
calidad de vida para esta población "significa tener paz y tranquilidad, ser cuidado y protegido por la familia con dignidad, amor y respeto, y tener satisfechas como ser social sus necesidades de libre expresión, decisión, comunicación e información" (Vera, 2007).

Las políticas públicas orientadas el bienestar social para el adulto mayor en algunos países están consolidadas y en otros aún falta fortalecimiento en la aplicación de las mismas. En los últimos años como consecuencias de la crisis económica y financiera, las prestaciones sociales han sufrido restricciones, recortes, retrasos, afectando la calidad del servicio.

La situación económica del adulto mayor en Colombia se caracteriza por la falta de recursos suficientes para brindar una mejor calidad de vida a la población mayor, este hecho ha obligado a la mujer a seguir participando en el mercado laboral. La tasa de ocupación para el grupo de 56 años y más, muestra un descenso entre 1991 y el 2000 al pasar del $31.1 \%$ al $28.4 \%$ y se registró un descenso de más de 10 puntos en 1991. Los estudios realizados por el Departamento Administrativo Nacional de Estadística -DANE- (2015) en el CENSO 2005 - indica que Colombia cuenta con una población total de 44.531 .384 millones de personas, de las cuales el $7 \%$ corresponde a adultos mayores y un efecto de incorporación por el orden de 80.000 ingresando cada año a las cifras de los mayores de 60 años, así en el 2030 el incremento anual será 4 veces mayor. Colombia pasará de 3 millones de personas mayores a 15 millones en el 2050. En pensiones la situación es crítica según los cálculos del Departamento Nacional de Planeación -DNP- (2015), para el año 2012 registran el porcentaje de personas que reciben pensión por edad en Colombia, puesto que la población económicamente activa, solo un $24 \%$ se encuentra afiliado al sistema pensional. Entre tanto el Ministerio de Trabajo y Seguridad Social a su vez, con relación a la mujer mayor, ha hecho una aproximación de diagnóstico a su situación actual en lo que tiene que ver con su identidad de género, actividades y ubicación geográfica y definió programas específicos en el tema de salud sexual y reproductiva para tener una mejor calidad de vida y fomento en la participación de la microempresa para las mujeres cabeza de familia. Inicia su desarrollo con el nombre de Revivir, actualmente se identifica como el Programa de Atención Integral para el adulto mayor.

Por otro lado, según la Encuesta de Condiciones de Vida de los Mayores de 2006, realizada por el Observatorio de Personas Mayores del IMSERSO (2014), el 31,9\% de las personas de 65 y más años, no pueden y necesitan ayuda para realizar una o varias de sus actividades de la vida diaria. La renta media equivalente de los mayores españoles en el año 2006 fue de 8.792 euros anuales, el valor resulta muy próximo al de la pensión media de jubilación, que en ese año garantizaba una renta anual bruta de algo más de diez mil euros. El sistema de pensiones de la Seguridad Social alcanzó el 1 de mayo de 2008 los 8.359.370 de pensiones contributivas en vigor, casi cinco millones son pensiones de jubilación y más de dos de viudedad. La pensión media del sistema fue de 719 euros mensuales, con importantes diferencias por clases y regímenes: la pensión media de jubilación era de unos cien euros más (819), mientras que la de viudedad era inferior en casi doscientos (529 euros mensuales). 
Por tanto, los bajos índices de inserción laboral, las altas tasas de desocupación, la informalidad laboral, la baja calidad en puestos de trabajo mal remunerados, genera altas tasas de pobreza, marginación y migración, afectando mayoritariamente a las personas adultas mayores. Las condiciones económicas de las personas mayores, aunque no son favorables, resultan menos precarias con respecto a otros grupos etarios de los colombianos. Es así como un $50.9 \%$ de la población con más de 65 años de edad se encontraba en situación de pobreza en el 2000, esto es más de 1.3 millones. En el informe del Departamento Nacional de Estadística -DANE- (2012) en su metodología de aplicación en la Encuesta Nacional de Demografía y Salud (ENDS) 2011, realizada para conocer la demografía y salud de la población colombiana, se rescatan temas centrados en el Adulto Mayor. Los resultados de las Características Generales en la ENDS, de un total de 17.574 adultos mayores entrevistados con una tasa de respuesta total del $92 \%$, son: "alrededor de la quinta parte de los adultos mayores no ha aprobado ningún año de educación, 58 \% ha cursado solo la primaria, 17 \% tiene secundaria y 5 \% tiene educación superior".

En cuanto a las condiciones laborales del adulto mayor en el contexto colombiano, antes de la Constitución de 1991, el concepto y marco legal que prevaleció respecto a la responsabilidad del Estado con relación a la persona mayor, era de carácter asistencial a discreción de los gobernantes y condicionada a la existencia de recursos del presupuesto. La obligación formal e institucional de dicha protección, estaba limitada a la responsabilidad de la familia por la manutención, puesto que no existía una normativa que desarrollará un sistema, para la financiación y aplicación de los recursos por parte del Estado.

En el mismo sentido, de acuerdo al Ministerio de Salud y Protección Social (2013), "cerca de una cuarta parte de los adultos mayores trabaja. Un $70 \%$ de ellos son trabajadores por cuenta propia, 13 $\%$ son peones o jornaleros y trabajadores familiares sin remuneración y $11 \%$ son obreros 0 empleados de empresas particulares o públicas... El $71 \%$ de las mujeres que trabaja son trabajadoras por cuenta propia, $9 \%$ son empleadas domésticas y $8 \%$ obreras o empleadas de empresa particular...Menos de la mitad de los adultos mayores trabajan a destajo por horas o por días ( $26021 \%$ respectivamente). Les siguen quienes reciben salario fijo ( $23 \%$ ) o les pagan por comisión o por porcentaje ( $15 \%$ ). A un $9 \%$ no le pagan por su trabajo, un $3 \%$ recibe pago en especie (ropa o comida) y el $2 \%$ recibe honorarios... Del total de adultos mayores que trabajan, el $74 \%$ tiene ingresos inferiores a un salario mínimo mensual (SMM), $17 \%$ recibe uno a menos de dos SMM, $3 \%$ de dos a menos de tres SMM y $6 \%$ tienen tres o más SMM...Entre los adultos mayores que no trabajan un $27 \%$ vive de la ayuda de los familiares que residen en el país y $4 \%$ fuera de él; y casi la tercera parte (28\%) son jubilados. El $9 \%$ vive de otros ingresos, hay un $13 \%$ que recibe subsidio de bienestar social para su supervivencia y $30 \%$ que no tiene ningún ingreso". 


\subsubsection{El adulto mayor en el entorno empresarial}

Los desafíos del envejecimiento poblacional, pasa por gestionar el talento humano en una sociedad competitiva y por definir e implementar políticas públicas hacía este sector de la población, como las contrataciones públicas socialmente responsables (Burzaco, 2016). Así, las transformaciones sociales y económicas han dejado una impronta en el perfil demográfico de los países. La aplicación de avances sanitarios, el mejoramiento nutricional, el acceso a la formación y capacitación, la ampliación de cobertura en salud ha influido en la longevidad poblacional, sin embargo las tendencias muestran cambios significativos en el relevo generacional, contribuyendo a elevar la productividad empresarial y mejorar las condiciones de vida de la población adulto mayor.

Las empresas han ido comprendiendo la importancia de este segmento del mercado, con poder adquisitivo, informado, globalizado, con disposición a disfrutar la vida y demandante de bienes y servicios, entre los que se menciona: el turismo, el ocio, los servicios asistenciales de todo tipo, los seguros médicos, los productos financieros, pensiones, incluso muchos de los adultos mayores que se encuentran en buenas condiciones, son quienes deciden acerca de los productos infantiles para sus nietos. Sin embargo, y a pesar de que su tendencia es creciente a nivel mundial, ellos se quejan de que se les deja de lado, y son sus hijos o las personas encargadas de su cuidado, quienes deciden; qué deben comer, vestir, dónde ir, cómo divertirse, entre otros.

Gracias a los avances científicos de la medicina y tecnológicos en la ciencia médica, especialmente en el campo de la farmacología, se prevé una extensión de la actividad física y mental de los adultos mayores, prolongando sus años de existencia, lo que significa que crecerá el número de hogares, donde vivan dos o más adultos mayores, debiendo tomar decisiones de compra y preferencia de marcas y productos, así como, la existencia de adultos mayores con más experiencia, formación y habilidades para ser valorados y aceptados en el mercado laboral, como capital humano valioso de la empresa, y no retirados de las organizaciones una vez cumplen sus años de pensión.

Para las empresas, como las de la Economía Social (Jorge \& otros, 2013) este segmento de población se convierte en un derrotero, debiéndose trazar estratégicas organizacionales, orientadas a mejorar la calidad de vida del adulto mayor, a través de la satisfacción de bienes y productos que reflejen las expectativas y deseos de dicho grupo poblacional, marcado con estrategias de responsabilidad social y mercadeo social. Así mismo, ésta tendencia debe reflejarse hacía una mayor especialización en la atención que se da en los hogares geriátricos, las residencias o centros de atención a mayores, analizándose como una oportunidad de contribución social y de empleo para profesionales como sicológicos y trabajadores sociales especializados en este segmento, dentro de un contexto empresarial social, mediante una red 0 asociación social que cuente con eslabones de tiendas, farmacias, hoteles, transporte, cosméticos, alimentos, recreación, estudio y elaboración de aparatos ergonómi$\cos$, de masajes y hasta de convenios con institutos de educación y otros que hagan la vida más placentera al adulto mayor. 
Finalmente, la relación empresarial y la responsabilidad social con el adulto mayor, se puede analizar desde diferentes enfoques, partiendo desde el enfoque liberal hasta el enfoque de las instituciones sociales, de los cuales se hace referencia en la tabla 2.

\section{Tabla 2 Teorías y enfoques de la responsabilidad social empresarial}

\begin{tabular}{|c|c|c|}
\hline Teoría & Enfoque & Autores \\
\hline \multirow{3}{*}{$\begin{array}{l}\text { Teorías políticas (enfoque en el uso } \\
\text { responsable del poder por parte de las } \\
\text { empresas en la área política) }\end{array}$} & Constitucionalismo corporativo & Davis $(1960,1967)$ \\
\hline & $\begin{array}{l}\text { Teoría del contrato social inte- } \\
\text { gral }\end{array}$ & Donaldson y Dunfee $(1994,1999)$ \\
\hline & $\begin{array}{l}\text { Ciudadanía corporativa } \\
\text { (empresarial) }\end{array}$ & $\begin{array}{l}\text { Wood y Lodgson (2002), Andriof y McIntosh (2001) } \\
\text { Matten y Crane (en prensa) }\end{array}$ \\
\hline \multirow{3}{*}{$\begin{array}{l}\text { Teorías integrales (enfocadas a la inte- } \\
\text { gración de las demanda sociales) }\end{array}$} & Management de asuntos & $\begin{array}{l}\text { Sethi (1975), Ackerman (1973), Jones (1980), } \\
\text { Vogel (1986), Wartick y Mahon (1994) }\end{array}$ \\
\hline & Management de Stakeholders & $\begin{array}{l}\text { Mltchell et al. (1997), Agle y Mitchell(1999), Rowley } \\
\text { (1997) }\end{array}$ \\
\hline & Desempeño social corporativo & $\begin{array}{l}\text { Carroll (1979), Wartick y Cochran (1985), Wood } \\
\text { (1991b) Swanson (1995) }\end{array}$ \\
\hline \multirow{3}{*}{$\begin{array}{l}\text { Teorías éticas (Enfocadas en hacer lo } \\
\text { correcto para obtener una sociedad } \\
\text { buena) }\end{array}$} & $\begin{array}{l}\text { Teoría normativa de } \\
\text { Stakeholders }\end{array}$ & $\begin{array}{l}\text { Freeman (1984, 1994), Evan y Freeman (1988), } \\
\text { Donaldson y Preston (1995), Freeman y Philips } \\
\text { (2002), Philips (2003) }\end{array}$ \\
\hline & Desarrollo sostenible & $\begin{array}{l}\text { Comisión Mundial de de Desarrollo y Medio } \\
\text { Ambiente (Reporte de Brutland) (1987), Gladwin } \\
\text { y Kennelly (1995) }\end{array}$ \\
\hline & El bien común & $\begin{array}{l}\text { Alford y Naughton (2002), Melé (2002), Kaku } \\
\text { (1997) }\end{array}$ \\
\hline
\end{tabular}

FUENTE: Adaptado de GARRIGA, Elisabet; MELÉ, Domènec. (2004): "Corporate Social Responsibility Theories: Mapping the Territory Pag. 51-71.

\subsection{La salud en el Adulto Mayor}

En 1946 la Constitución de la Organización Mundial de la Salud (O.M.S., 2014,1), introdujo el concepto de salud, como "un estado de completo bienestar físico, mental y social y no solamente la ausencia de afecciones y enfermedades... es uno de los derechos de todo ser humano...". Salud y 
enfermedad, forman parte de un proceso continuo, móvil que refleja el grado de adaptación del hombre como ser bio-social a las condiciones biológicas y sociales del medio. La salud es un estado de equilibrio, con determinado grado de componente subjetivo, entre lo biológico y lo psíquico con el medio ambiente social, cultural y natural pero este concepto no se ajusta a los ancianos. La salud de las personas mayores se va deteriorando, lo que se traduce en una mayor demanda de atención y oferta del mercado, imponiendo relaciones recíprocas intergeneracional y familiares, así como el cuidado dentro de las prioridades de las políticas públicas.

En la Tabla 3 se presenta algunos datos representativos de la persona mayor, en los dos contextos de estudio, Colombia y España.

\subsection{Entorno residencial de las personas Adulto Mayor}

Los primeros hogares para adultos mayores fueron llamados hogares geriátricos, aparecen en Europa en el siglo XVI, destinados a albergar personas mayores vagabundos y con problemas mentales. A través de los años, las residencias han sido una solución de las sociedades para atender a los ancianos. En 1834 surgió en Gran Bretaña la necesidad de acoger y cuidar a numerosos grupos de adultos mayores sanos, enfermos y perturbados mentales, dando inicio de manera más formal los asilos de ancianos (Cape, 1982).

Actualmente las instituciones que acogen a las personas mayores en Colombia, se conoce como Hogar Geriátrico u Hogares para Adulto Mayor. En España esa expresión se usó en los siglos XVIII y XIX, hoy en día son conocidos como Establecimientos o Centros Residenciales para personas mayores. "Son considerados Establecimientos Residenciales para personas mayores las entidades que tienen como fin brindar servicios de alojamiento, alimentación, higiene, recreación activa o pasiva y atención médica y psicológica no sanatorial a personas mayores de 60 años, en forma permanente o transitoria, a título oneroso o gratuito" (CEDOM, 2008). Se entiende por centros residenciales a aquellos "alojamientos colectivos para personas mayores bajo diferentes modelos: residencias, incluidas la mini-residencias; viviendas o pisos tutelados; centros psicogeriátricos; centros sociosanitarios; conjuntos residenciales" (Equipo Portal Mayores, 2010).

El Hogar Geriátrico (HG) se concibe dentro de los servicios sociales, que se utilizan para describir aquellas actividades organizadas, cuyo objetivo es ayudar a la adaptación mutua entre los individuos y su ambiente social. El personal es multidisciplinario de asistencia médica y social, incluye médicos, enfermeras, trabajador social, terapeuta ocupacional, fisioterapeuta, dietista, personal de asistencia a pacientes, y otras personas encargadas de los servicios propios de estas instituciones. La edad de ingreso de los adultos mayores no debe ser inferior a 60 años, siempre que el estado social o psico-físico de la persona lo justifique. La reglamentación establece casos en que se procede a tal excepción, resguardando la dignidad de las personas y respetando la concepción y fines de las Residencias, garantizando las condiciones que preserven la seguridad, salubridad e higiene de los 


\section{Tabla 3. Consideraciones de la persona Mayor en Colombia y España}

\begin{tabular}{|c|c|}
\hline Colombia & España \\
\hline $\begin{array}{l}\text { "La proporción de mujeres mayores es superior que la de los hombres. En eda- } \\
\text { des avanzadas se alcanza un mayor volumen de mujeres en comparación con hom- } \\
\text { bres". }\end{array}$ & $\begin{array}{l}\text { "El sexo predominante en la vejez es el femenino. Hay un } \\
32,9 \% \text { más de mujeres (4.940.008) que de hombres } \\
(3.717 .697)(2016) \text { ". }\end{array}$ \\
\hline $\begin{array}{l}\text { "Uno de cada } 10 \text { adultos mayores considera excelente o muy bueno su estado de } \\
\text { salud, } 40 \% \text { lo considera bueno, } 44 \% \text { regular y } 6 \% \text { malo". }\end{array}$ & $\begin{array}{l}\text { El } 50,5 \% \text { del tiempo por vivir en los hombres es con buena } \\
\text { salud, mientras que sólo el } 38,5 \% \text { en el caso de las muje- } \\
\text { res está en buenas condiciones. }\end{array}$ \\
\hline "Se espera que el adulto mayor alcance un nivel de 76 años en $2020 "$. & $\begin{array}{l}\text { "La esperanza de vida es uno de los indicadores princi- } \\
\text { pales que reflejan consecuencias de las políticas sanita- } \\
\text { rias, sociales y económicas". }\end{array}$ \\
\hline $\begin{array}{l}\text { "Entre los beneficiarios de protección social hay más mujeres que hombres, per- } \\
\text { sonas de } 80 \text { a } 89 \text { años, de la zona rural, personas viudas, que trabajan pero no les } \\
\text { pagan o que no trabajan". }\end{array}$ & $\begin{array}{l}\text { "Ligera disminución de la vida saludable en ambos sexos } \\
\text { a partir de 2008". }\end{array}$ \\
\hline $\begin{array}{l}\text { "El } 71 \% \text { de los adultos mayores con problemas de salud acudió al servicio de salud, } \\
8 \% \text { trató su enfermedad con remedios caseros, } 9 \% \text { se auto-medicó, } 3 \% \text { acudió a } \\
\text { la farmacia, } 2 \% \text { a la medicina tradicional y } 1 \% \text { a terapias alternativas. De los que } \\
\text { acudieron al médico y les formularon medicamentos, afiliados a la EPS al } 62 \% \text { le } \\
\text { dieron todos las medicinas, al } 19 \% \text { solo una parte y al } 17 \% \text { no se los dieron. El } 22 \% \\
\text { estuvieron hospitalizados (2011). De ellos, } 69 \% \text { por enfermedad, } 22 \% \text { por cirugía } \\
\text { y un } 8 \% \text { por algún tipo de accidente. La EPS pagó totalmente la hospitalización en } \\
\text { el } 61 \% \text { de los casos y en el } 34 \% \text { lo hizo parcialmente". }\end{array}$ & $\begin{array}{l}\text { "Las personas mayores suponen el } 44,4 \% \text { de todas las } \\
\text { altas hospitalarias y presentan estancias más largas que } \\
\text { el resto de la población (2015)". }\end{array}$ \\
\hline $\begin{array}{l}\text { "Las enfermedades más frecuentes: coronarias, neumonía o bronconeumonía, } \\
\text { hipertensión arterial, artritis, epilepsia y cáncer. Entre las mujeres se presentaron } \\
\text { mayores niveles de hipertensión y artritis, mientras que en los hombres la neumo- } \\
\text { nía". }\end{array}$ & $\begin{array}{l}\text { "Las enfermedades circulatorias }(21,4 \%), \text { respiratorias } \\
(16,4 \%) \text {, digestivas }(11,9 \%) \text { y neoplasias }(11,2 \%) \text { son las } \\
\text { causas más frecuentes de asistencia hospitalaria". }\end{array}$ \\
\hline $\begin{array}{l}\text { "El } 45 \% \text { de los adultos mayores pertenece al régimen contributivo, otro } 45 \% \text { al } \\
\text { subsidiado, } 3 \% \text { al régimen especial y } 6 \% \text { no tiene afiliación a ningún sistema de } \\
\text { salud". } \\
\text { "Los adultos mayores que asisten a los programas de alimentación son en su mayo- } \\
\text { ría varones, personas de } 70 \text { a } 84 \text { años y de } 90 \text { a } 94 \text { años". }\end{array}$ & $\begin{array}{l}\text { "En total hay 9,4 millones de pensiones en el sistema de } \\
\text { la Seguridad Social...La mayor parte de las pensiones del } \\
\text { sistema de Seguridad Social corresponde al régimen } \\
\text { general (6,7 millones). - Prácticamente la totalidad de las } \\
\text { personas mayores recibe alguna prestación económica } \\
\text { del sistema público de pensiones (directamente o a tra- } \\
\text { vés de la pensión del cónyuge)". }\end{array}$ \\
\hline $\begin{array}{l}\text { "El } 84 \% \text { vive acompañado por su familia y el } 6 \% \text { en la soledad...Un } 14 \% \text { son bene- } \\
\text { ficiados de un programa alimentario del Estado. El } 8 \% \text { recibe alimentos de un pro- } \\
\text { grama de protección social y un } 6 \% \text { del programa nacional de alimentación". }\end{array}$ & $\begin{array}{l}\text { "La proporción de mujeres mayores que vive en soledad } \\
\text { supera a la de hombres (2015: 28,9\% frente a 14,1\%)". }\end{array}$ \\
\hline $\begin{array}{l}\text { "El } 71 \% \text { hombres está casado o vive en unión libre, el } 37 \% \text { de las mujeres lo están". } \\
\text { "El } 41,7 \% \text { son hombres jefes de hogar y el } 18.5 \% \text { mujeres jefes de hogar. Tres de } \\
\text { cada cinco se sienten afectados emocionalmente por la salud". }\end{array}$ & $\begin{array}{l}\text { "El } 60,5 \% \text { de las personas mayores están casadas ( } 77,9 \% \\
\text { de los hombres, } 47,3 \% \text { de las mujeres) y el } 28,9 \% \text { viudas } \\
\text { ( } 11,5 \% \text { y } 42,2 \% \text { respectivamente) (2011)". }\end{array}$ \\
\hline
\end{tabular}

FUENTE: Elaboración propia a partir de los informes: los resultados del envejecimiento demográfico en Colombia (2013), informe envejecimiento en red (Abellán, Ayala, Pujol, 2017), y envejecer en Colombia (Santos \& Valencia, 2015). 
residentes y estimulen sus capacidades, el pleno respeto como personas, promoviendo los vínculos con el núcleo familiar y la comunidad a la que pertenecen. Son entidades que tienen como fin brindar servicios de alojamiento, alimentación, higiene, recreación y atención médica y psicológica no sanatorial a personas mayores de 60 años, en forma permanente o transitoria, a título oneroso o gratuito.

El hogar geriátrico facilita la buena convivencia y un bienestar general, Sin embargo, se presentan quejas por parte de los adultos mayores por la falta de afecto en estos hogares, ya que la relación es la de recibir un servicio; las necesidades afectivas o de autoestima, como el amar y ser amados, no están satisfechas y a algunos, esta situación les trae manifestaciones de frustración y de aversión, aunque reconocen que es un camino privilegiado, porque no todos lo pueden tener y la familia se beneficia cuando no puede atender al adulto mayor enfermo en casa. Según diversos autores (Rodríguez \& Marbán, 2015; Sajardo \& Ribas, 2014) la Ley del voluntariado y del tercer sector recobran importancia en este contexto a partir de la $\mathrm{RS}$, donde la persona mayor tiene el derecho a mantener o recobrar el Bienestar. (De Lorenzo \& Sempere, 2016).

En Colombia existe una normativa sobre las instituciones geriátricas, por la que se reglamenta la parte higiénico-sanitaria e infraestructura física de estos centros. Es así como el Protocolo Adicional de la Convención Interamericana de Derechos Humanos en materia de Derechos Económicos, Sociales y Culturales, "Protocolo de San Salvador", (1988), fue ratificado por Colombia mediante la ley 319 de 1996, la cual establece en su artículo 17 - Protección de los Ancianos. Sin embargo, el ámbito de ayudas en las Residencias para adultos mayores, especialmente de estratos sociales 3 y más en Colombia, por parte del Estado, es poco. Los programas de 'centros de tercera edad' y colegios son los que más aportan con un $22 \%$ cada uno, seguido por las instituciones universitarias (Congreso de Colombia, 1996). Es necesario acudir a convenios con colegios de secundaria, donde los jóvenes estudiantes del grado once realizan un trabajo social cumpliendo con 80 horas de servicio para los adultos mayores y con universidades donde los estudiantes realizan prácticas sociales 0 académicas, también reciben apoyo solidario de otros hogares del mismo sector, es decir que han formado redes 0 asociaciones que comparten ciertos principios, valores, preferencias, estilos de vida, además se encuentra que deben acudir en menor proporción según la ayuda que logran por parte de las fundaciones y los centros de lúdica y de salud.

En España la posibilidad de ayuda externa está presente en las Residencias. Se trata de una acción continuada en el tiempo, mediante un plan o programa preventivo y curativo. El personal de los centros de salud son los que más prestan sus servicios de forma voluntaria (médicos y enfermeras). También los centros infantiles (escuelas, colegios) fomentando las "relaciones intergeneracionales" y de compartir e intercambiar, como los centros lúdicos de diverso tipo para fomentar espacios de esparcimiento. 


\subsection{Componentes de la calidad de vida en la tercera edad}

La satisfacción de las necesidades de las personas, es lo que condiciona la llamada "Calidad de Vida" y ésta es a su vez, el fundamento del bienestar social. La persona es un ser de necesidades múltiples e interdependientes, por ello las necesidades humanas deben entenderse, como un sistema en que las mismas se interrelacionan e interactúan y se satisfacen en tres contextos: en relación con uno mismo (Eigenwelt), en relación con el grupo social (Milwelt) y en relación con el medio ambiente (Umwelt). La calidad de vida en la tercera edad debe estar ajustada a la satisfacción de sus necesidades (Doyal, y Gough, 1994), a la esperanza de vida, estado de salud, estado funcional, incapacidad y riesgo.

Para Berenice L. Neugarten en 1974, citado por Espinosa (1995), la satisfacción de vida de los envejecidos se define según los siguientes criterios: satisfacción en las actividades diarias, significado de la vida haciéndose responsable de la misma, percepción del logro de metas de vida, autoimagen y actitud hacia la vida. Entre tanto Fernández-Ballesteros (1993; 2000), resalta cómo actualmente todos los planes y programas de servicios sociales dirigidos a los mayores y a otros grupos poblacionales tienen como objetivo incrementar la calidad de vida para alcanzar el estado de bienestar. Aclara que, el concepto de calidad de vida en las personas mayores, lleva consigo factores importantes como es la autonomía. Rechaza la igualdad que algunos autores han querido dar a la calidad de vida, solo con el estado de salud del individuo, da importancia a factores como habilidades funcionales, relaciones sociales, actividades de ocio y satisfacción y factores socio ambientales: apoyo social, condiciones económicas, servicios de salud y sociales, calidad del ambiente y aspectos culturales.

El concepto de calidad de vida establece, cuáles son las mejores condiciones para el bienestar del adulto mayor, por ejemplo: contar con una jubilación, seguro médico y hasta un buen trato preferencial en los diferentes entornos. La percepción sobre la adultez ha ido cambiando con los años; antes, simplemente la persona se alejaba de las labores cotidianas demandadas por el trabajo, además del factor demográfico donde la mayoría de la población vivía en el campo, la tierra producía, la escasez de alimentos era poca y el adulto mayor era acogido en el hogar familiar. Las personas adultas mayores eran valoradas y consideradas sabios e historiadores, La esperanza de vida, era más baja que la actual y la expectativa de vida era escasa y no pasaban de los 60070 años. En la actualidad la mayoría de la población vive en las ciudades y la acumulación de riquezas resulta más difícil, por la devaluación y la misma inseguridad, no hay tiempo en las familias para cuidar del adulto mayor y se opta por una residencia u hogar geriátrico, además que la esperanza de vida es mayor. 


\section{Análisis de resultados. Una Mirada desde la Responsabilidad Social hacía el Adulto Mayor}

La recesión económica mundial como resultado de un deliberado y desmedido auge del sistema capitalista, la contaminación ambiental y el ineficiente uso de los recursos naturales, sumado a la caótica crisis social que atraviesa el planeta; hace necesario pensar en estrategias funcionales y proactivas desde las organizaciones empresariales en red, que contribuyan de forma efectiva y directa a reducir los impactos nefastos que dichas prácticas ocasionan para la humanidad. Así mismo, el uso racional de estrategias de sostenibilidad y R.S., garantiza a la organización que las aplique, un factor determinante de armonía, confianza, reputación, credibilidad y respeto, tanto de los públicos internos como externos (Muñoz, 2015). Es así como, promover las prácticas de RS en las organizaciones empresariales y en los profesionales, conlleva a generar mayores niveles de competitividad y perdurabilidad integral, con un alto nivel de sostenibilidad y sustentabilidad gerencial.

En la medida que se instrumente iniciativas que faciliten la comprensión y apropiación de la R.S., como herramienta de competitividad en los contextos donde la población en cuestión se desenvuelva, el adulto mayor contará con un envejecimiento activo a fin de mejorar la calidad de vida a medida que envejece (Muñoz \& otros, 2015) ${ }^{5}$. Las personas mayores que se retiran del trabajo y las que están enfermas o viven en situación de discapacidad pueden seguir contribuyendo activamente con sus familias, semejantes, comunidades y naciones. Por lo tanto, se debe a) sensibilizar al sector empresarial social sobre el impacto y valor de incorporar la RS, hacia el adulto mayor en la estrategia de negocios y b) promover los cambios culturales y organizacionales en las empresas para mejorar su competitividad a través de la RS hacia el adulto mayor. Todo lo anterior en un contexto de política de calidad y ética del desempeño, teniendo presente a la comunidad académica, gubernamental, empresarial y claro está, la comunitaria a través de la gestión responsable de los impactos educativos, cognitivos, laborales, sociales, productivos y económicos que genera cada ente (Martínez, 2011).

El caso de la persona adulto mayor debe ser incluida en los procesos que por convicción se generan en la comunidad, en las instituciones académicas y en las empresas como RS. Resultados de la investigación (Osorio \& otros, 2017), muestra que en el caso de los que residen en un Centro asistencial, pese a que los familiares están obligados a enterarse de la situación del adulto mayor en la Residencia, especialmente por el tema de pagos de mensualidad, son muchos los que los abandonan completamente, un 14\% dejan de pagar la mensualidad mientras un $10 \%$ los abandonan afectivamente. La justificación de la perdida de contacto totalmente con sus familiares, para algunos es por

5.- Los autores son los coordinadores del monográfico: Responsabilidad Social de la Empresas: Innovación y sostenibilidad", 2015, 85, 304 pp. El lector encontrará artículos relacionados con 1) innovación y creatividad, 2) sostenibilidad y desarrollo económico 3) cambio en el paradigma empresarial, hacia una economía más social, 4) determinantes, aplicación y difusión de la R.S., y 5) bienestar y eficiencia. 
cuestiones de distancia, manifiestan estar fuera del país; otros, según los encuestados (administrativo), han deteriorado sus lazos afectivos con el familiar, quien se limita solo a girar el dinero del mantenimiento de la persona mayor.

También, en relación con las actividades que realizan los adultos mayores en las residencias, tienen componentes sociales y terapéuticos; sin embargo, el componente cultural no tiene mucha importancia. El factor que más influye en la motivación es la terapia física, manifestando el adulto mayor la disposición a trabajar por salud (67\%) en las sesiones de fisioterapia o de ejercicios. Igualmente, el entretenimiento con los juegos de mesa, en especial el dominó y el parchís, es parte de la vida diaria en las residencias. Sin embargo, se aprecia una cantidad considerable de adultos mayores reacia a todo tipo de actividad propuesta y prefiere sentarse a ver la televisión (29\%) o simplemente, sentarse a pensar y a recordar el pasado (21\%). Las manualidades (25\%), es otro espacio de participación. Las actividades que menos llaman la atención a ésta población, es el baile y la recreación, con un $8 \%$ cada una. Las actividades espirituales tienen un peso del $12 \%$.

Las compras de alimentos en las residencias se ven condicionadas por las características de las dietas específicas que deben seguir los adultos mayores. En la mayoría de hogares (63\%) se realizan las compras para todos y por lo tanto todos consumen lo mismo, aunque algunos paguen más dinero que otros. Cabe resaltar que en España a diferencia de Colombia, el adulto mayor se siente más seguro en la Residencia, lugar donde se les ofrece servicios integrales y están atendidos por profesionales expertos y cualificados; la cercanía de los servicios de higiene (personal y de las instalaciones), alimentación, vestido; cuidados de la salud: medicinas, consultas, curas, etc.; cuidados psicosomáticos: fisioterapia, ejercicios de memoria, actividades de ocio y entretenimiento; y, sobre todo las relacionales, el adulto mayor en la residencia está con otros de su misma edad. Esto no quiere decir que en sus casas no estaban seguros, sí pero de diferente manera.

Es así, como se encuentra que desde diferentes eslabones se puede contribuir a un mejor bienestar para la población adulto mayor a través de la RS, que empieza por la persona misma, seguido de la responsabilidad familiar, empresarial, institucional (Estado) y la pública (comunidad y administración pública), identificando prácticas reales, como factor determinante de productividad y competitividad empresarial o institucional, conducente a la apropiación por convicción -Compromiso solidario por el desarrollo interno y externo-.

La propiedad conjunta y de gestión democrática de la dimensión empresarial, debe impulsar el trabajo en equipo en todo lo que en la empresa pueda establecerse. Es necesario inspirar a emprender prácticas creativas e innovadoras sobre la $\mathrm{RS}$, como una de las formas de hacer negocios que tiene en cuenta aspectos sociales, económicos y ambientales. Integrado con el respeeto por los valores éticos, personales, comunidades y del medio ambiente, con el fin de generar valor a través de un marketing interno y externo. 
En el caso de las residencias para adultos mayores, las intervenciones en prestación de servicios, se observa desde la relación con los trabajadores, los voluntarios y las familias registrando las visitas, además de fijar planes y programas para lograr convenios con aliados estratégicos que generen recursos 0 intervenciones propias en favor del adulto mayor. Igualmente se encuentran relaciones corporativas en la gestión social y cooperación y solidaridad. Son visibles las estrategias integrales y de contenido social, sin embargo, existen falencias en innovación en procesos y productos propios para la actividad y movilidad física del adulto mayor. En Colombia, aún falta promoción, articulación e iniciativas de R.S. interna y externa, puesto no existen lineamientos claros en un sistema de gestión de R.S. que apoye iniciativas y propuestas para gestionar la participación o vínculos con otras entidades de diferentes sectores. Lo cierto es que, en los dos contextos del estudio, es decir, en Colombia y en España, se requiere coordinar y promover iniciativas de cooperación nacional e internacional, que permitan el vínculo con diferentes stakeholders, con el fin de lograr la satisfacción de las necesidades y deseos, así como, la calidad y pertinencia del servicio percibido por el adulto mayor, tanto en las residencias como en el entorno externo donde residen.

Por lo tanto, integrar la R.S. a la gestión empresarial e institucional, como un enfoque estratégico que agrega valor a la cultura organizacional, potencia los niveles de competitividad y contribuye al crecimiento empresarial de la región y del país (Salinas \& Otros, 2016) ${ }^{6}$. Es necesario entonces, instrumentar iniciativas que faciliten la comprensión y apropiación de la RS, como herramienta de competitividad, además de sensibilizar sobre el impacto y valor de incorporar la RS en la estrategia de negocios de las empresas y las acciones en el sector público. La economía social, a través de las empresas y la sostenibilidad del Estado de Bienestar (paradigma del Estado), se vislumbra como un tratamiento holístico en la co-responsabilidad hacía las personas en estado de escasez y 'menor capacidad física' como son las personas mayores (Merino, 2016).

La R.S. desde la perspectiva sistémica: trihélice en un balance con alianzas público - privadas (Estado, sector productivo y academia) enfocada con estrategias de cohesión y desarrollo de gestión sistemático, dirija el proceso desde el 'punto $\mathrm{A}$ al punto B' con la participación de cada una de las personas involucradas con el bienestar de las personas mayores en actividades sociales, económicas, culturales, deportivas, recreativas, de voluntariado y de innovación, creando o generando facilidades para el desplazamientos de dicha población (Hernández \& Otros, 2016). Por ejemplo: desde la academia es posible a través de programas como ingeniería biomédica, qué aparatos ergonómicos contribuyan a mejorar su capacidad física y de movilidad; desde las áreas de mercadeo y la administración, gestionar para satisfacer mejor las necesidades y deseos inherentes de la población mayor, incrementando y manteniendo así un mejor bienestar personal y calidad de vida. (Osorio, 2010).

6. Los autores son coordinadores del monográfico: Responsabilidad Social, Administración Pública y Buen Gobierno, 2016, 87. Los once artículos que se recogen desarrollan planteamientos teóricos y experiencias relacionadas con la Responsabilidad Social en las Administraciones (RSA), en las Organizaciones Sociales (RSO) y en el Tercer Sector (RSTS). 
Una sociedad para todas las edades incluye el objetivo de que las personas mayores tengan la oportunidad de seguir contribuyendo a la sociedad. La contribución social y económica de estas personas, va más allá de sus actividades económicas, ya que con frecuencia esas personas desempeñan funciones cruciales en la familia y en la comunidad. Los servicios de prevención de las situaciones de dependencia y los de promoción de la autonomía personal, están contemplados y regulados en la Ley de la dependencia, pero es la sociedad civil, desde la empresa y la academia a través de alianzas quienes pueden generar a éste segmento mejores servicios y productos pero también incrementar posibilidades de ocupación de calidad para otras personas a través del emprendimiento 0 intra-emprendimiento social enmarcado en la ética (aplicación de valores y principios solidarios)

El incremento de la población mayor requiere de mejores y más atenciones, en la actualidad los medios y recursos socio-sanitarios son insuficientes. Para alcanzar una longevidad saludable, estilos de vida satisfactorios, mantenimiento de las reservas funcionales, prevención de enfermedades y discapacidades, y una sociedad más amigable con las personas adultos mayores, es necesario analizar aspectos como:

- Interacción - Formación - Investigación:

- Relaciones con comunidades.

- Diálogo de saberes con comunidades - Retroalimentación.

- Práctica de estudiantes y egresados.

- Formación multi-direccional.

- Investigación participativa.

- Investigación fundamental.

- Ventajas de la implementación de la Responsabilidad Social:

- Adopción de visión - convicción.

- Mejorar imagen.

- Construir Relaciones humanizadas.

- Vínculo más sólido con usuarios de salud y asociados.

- Desarrollar la atención de pacientes bajo la noción de derechos y no como "consumidores de salud".

- Mayor grado de pertenencia de los empleados dentro y fuera de la organización.

De acuerdo a Pino \& Sáez (2014) El desarrollo de la competencia social de los individuos reforzando el fin humanista durante el proceso de formación, puede conducir a formar gestores de cambio que asumen la participación en acciones solidarias y de servicio como uno de los propósitos del valor social del conocimiento. 


\subsection{El talento humano en la responsabilidad social}

El talento humano es un activo estratégico en el funcionamiento de la sociedad, es un nuevo paradigma que se centra en las capacidades de las personas y en los resultados; en la medida que se crea talento humano como capital y se actúe en consecuencia, se podrán aumentar los beneficios e incluso incrementar la satisfacción personal. El desarrollo del talento humano como ventaja competitiva en la gestión de los centros asistenciales hacia las personas mayores, es un tema relevante hoy y lo será en el futuro, porque convivimos con las crisis económica y social y con las trasformaciones de las empresas. Aquellas empresas que hayan interiorizado la importancia de contar con los mejores equipos humanos y de construir el compromiso con sus profesionales gozarán de posiciones privilegiadas. Es así como los cambios demográficos, los retos y oportunidades, no sólo hay que analizarlos, estudiarlos sino que hay que comprenderlos como un elemento clave para el diseño de políticas públicas, para que las empresas capten talento humano, atesoren al adulto mayor como capital valioso de experticia y en general para recrear una nueva agenda de gestión del conocimiento que conduce al desarrollo social, económico y ambiental.

El talento es igual a recursos y este a su vez es igual a capital humano, y por ende a resultados, con ingredientes básicos como la capacidad, compromiso con la organización y la acción para desarrollar estrategias en pro de la productividad, la innovación y la competitividad empresarial. Por tanto, la persona mayor juega un papel preponderante, en el proceso de gestión estratégica del talento, se requiere tenerlo en cuenta en la planificación de la empresa e identificarlo dentro y fuera de la misma, impulsando desarrollando y reconociendo y a la vez que reteniéndolo para generar capital intelectual y gestión del conocimiento en pro de la mejora en los procesos y métodos.

El desarrollo implica una comprensión holística y de la complejidad de la comunidad con la cual se trabaja (Osorio, 2010). La figura 1 representa el Patrimonio Social (Es), como la sumatoria de riqueza (Bienes y Derechos de una comunidad), llamados satisfactores, el cual esta generado por el desarrollo social más el beneficio colectivo; causado por el compromiso comunitario y el impacto social generado por la responsabilidad Social familiar (RSF). Entre tanto, el activo Social (Acs): representa las necesidades básicas satisfechas -NBS- y deseos de la comunidad, generado por la productividad más la competitividad, causado por la socialización del conocimiento más la aplicación de resultados bajo los procesos de la responsabilidad social empresarial, institucional y pública (RSE) (RSI) (RSP), conllevando a la salud económica, familiar y social. De otro lado, el pasivo social (Ps): representa las necesidades básicas insatisfechas -NBI- generado por el deterioro de la salud social y causada por las obligaciones incumplidas o no generadas a satisfacción por el nivel de compromiso del Estado para con la sociedad. Por ello es necesario de un líder que mueva sistémica y sistemáticamente los procesos de RS para fortalecer, generar condiciones, recuperar valores y construir sociedad solidaria en pro de la transferencia del desarrollo social sostenible y la capacidad de generar a la persona adulta mayor una longevidad vida más digna, a través de la inclusión de la persona misma o el apoyo de las nuevas generaciones. 


\section{Figura 1. El talento humano y la Responsabilidad Social en la riqueza social}

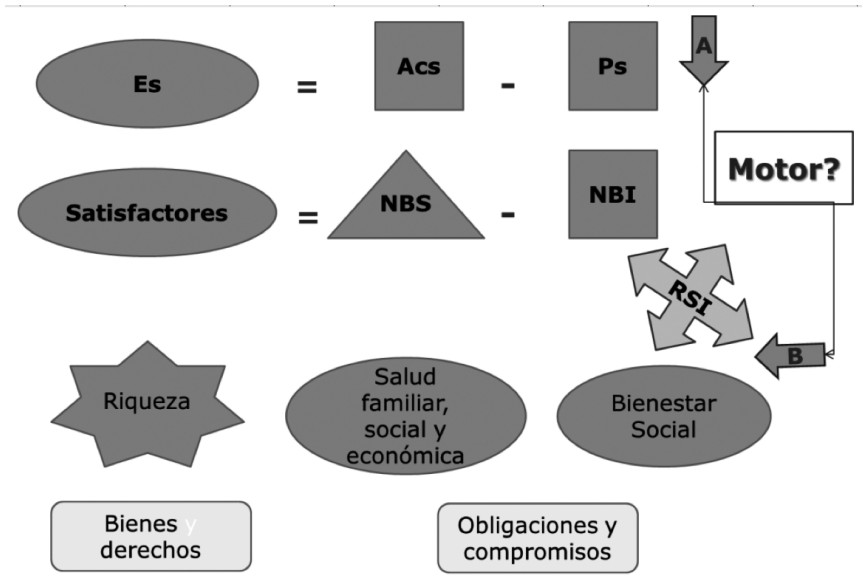

FUENTE: Elaboración propia (Osorio, 2016).

\section{Conclusiones}

La transición demográfica, hace que se reflexione sobre el crecimiento y especialmente el incremento acelerado de la población adulto mayor con una relación de la tasa de dependencia demográfica, generando un impacto en el sistema de salud, aunado al sistema pensional que a futuro puede estar colapsado por razones de cobertura y bajo financiamiento, precisando la necesidad de generar políticas públicas con condiciones mínimas, como destinar mayores recursos para el cuidado del adulto mayor en una responsabilidad compartida (familia - Estado), cotización de pensiones a edad más temprana entre otros, puede presentarse un impacto socio-económico negativo y por ende, el incremento de los índices de mortalidad como consecuencia de la llamada "enfermedad del desarrollo" va a tener un crecimiento mucho más alto.

El fenómeno del proceso de envejecimiento de la población, influye en el crecimiento económico, el ahorro, la inversión, el consumo, los mercados de trabajo, las pensiones, la tributación y las transferencias intergeneracionales. En lo social, incide en la atención de la salud, la composición de la familia, las condiciones de vida, la vivienda entre otros. Por lo que requiere de atenciones prioritarias, aún faltan medios y recursos socio-sanitarios conducentes a lograr una longevidad satisfactoria, esti- 
los de vida saludables, así como, estrategias de prevención de enfermedades y discapacidades con la población mayor.

El proceso de transición demográfica que ha tenido lugar en Colombia y España, en las últimas décadas, ha modificado el perfil poblacional de estos países. La heterogeneidad en este aspecto implica diferencias en la disminución del crecimiento de la población y el envejecimiento de las estructuras de edad, que a su vez inciden en el tipo y la magnitud de los problemas que deberán encarar en las próximas décadas. El envejecimiento y sus consecuencias es un proceso ineludible, pero previsible, cuantificable y, por lo tanto, manejable, si se tiene en cuenta de forma previsible y prospectivamente.

Es evidente que en la actualidad el adulto mayor llega con mejores condiciones que antes y pasan a ser actores más activos en la sociedad como consecuencia de la gestión de la edad en el lugar de trabajo, la preparación consciente y formación hacia la jubilación o el retiro. Las pensiones contributivas se han incrementado, 1 de cada 4 adultos mayores recibe una pensión contributiva por vejez. Sin embargo el futuro es menos alentador y los retos como el acceso a servicios de atención de salud de calidad para éste grupo poblacional es aún mayor, los ingresos para costear dicho 'derecho' es cada día menor, mientras el requerimiento de una mayor atención a las personas en situación de dependencia, a través de una prestación de servicio público/privada y la importancia de que las personas mayores estén involucradas en la agenda pública es una necesidad cada vez más imperante.

El llamado va dirigido a la necesidad de identificar, no solo factores demográficos que determinen el envejecimiento de la población. Se trata de lograr conseguir una mirada holística del sector empresarial, a través de la búsqueda de la realidad social y actual de un segmento de mercado en crecimiento, además de la importancia de las políticas gubernamentales y sociales vigentes para la protección de ésta población adulto mayor. Recolectando información sobre las transformaciones demográficas y los desafíos actuales y a futuro, según la transición poblacional y las características del envejecimiento conducentes al bienestar, la calidad de vida y la responsabilidad social de todos.

La necesidad de crear servicios apropiados para la población mayor, garantizando el acceso de calidad a los servicios sociales, considerando la capacitación de las personas que cuiden personas. El enfoque de la Atención Centrada en la Persona, exige nuevas competencias profesionales, requiere un "plus" de profesionalidad y trabajo en equipo. Para ello es preciso fomentar el desarrollo de acciones de formación, intercambio de experiencias y el fomento de buenas prácticas.

El adulto mayor, debe ser incluido en los procesos de la comunidad, planes familiares, propósitos de las instituciones académicas y dentro de los programas de RS de las empresas. Un elemento a resaltar de los resultados, es que a pesar, de que el adulto mayor necesita atención especializada, estos son abandonados, un $14 \%$ de los familiares dejan de pagar la mensualidad, mientras un $10 \%$ los abandonan afectivamente. También, está el familiar, que solo se limita a pagar la mensualidad, justificando su ausencia y falta de afecto a las distancias. 


\section{Referencias bibliográficas}

ABELLÁN, A., AYALA, A. \& PUJOL, R. (2017): "Un perfil de las personas mayores en España, 2017. Indicadores estadísticos básicos", Informes Envejecimiento en red, 15: 48.

http://envejecimiento.csic.es/documentos/documentos/enred-indicadoresbasicos17.pdf

BANCO MUNDIAL (2015): Expectativa de vida al nacer, total (años).

https://datos.bancomundial.org/indicador/SP.DYN.LE00.IN

BURZACO, M. (2016): "Contrataciones públicas socialmente responsables: necesidad de reconsiderar el potencial de la contratación pública en la consecución de objetivos sociales", CIRIEC-España, Revista de Economía Pública, Social y Cooperativa, 86, 281-310.

CAPE, R. (1982): Geriatría, Salvat, Barcelona.

CEDOM (2008): Dirección general centro documental de información y archivo legislativo. Sección 9: de la sanidad educación y cultura. Buenos Aires, http://www.cedom.gov.ar; citado 19 Agosto 2011.

COMISIÓN EUROPEA (2011): Comunicación de la Comisión al Parlamento Europeo, al Consejo, al Comité Económico y Social Europeo y al Comité de las Regiones. Estrategia renovada de la UE para 2011-2014 sobre la responsabilidad social de las empresas, Bruselas, http://www.europarl.europa.eu/meetdocs/2009_2014/documents/com/com_com(2011)0681_/com_com(2011) 0681_es.pdf

CONGRESO DE COLOMBIA (2008): Ley 1251 de 2008, por la cual se dictan normas tendentes a procurar la protección, la promoción y la defensa de los derechos de los adultos mayores. En: Diario Oficial No. 47186.

CONGRESO DE COLOMBIA (1996): Ley 319 de 1996, por la cual se aprueba el Protocolo Adicional a la Convención Americana sobre Derechos Humanos en Materia de Derechos Económicos, Sociales y Culturales "Protocolo de San Salvador", suscrito en San Salvador el 17 de noviembre de 1988.

COLOMBIA, Departamento Administrativo Nacional de Estadística (2015): Censo General 2005, http://www.dane.gov.co/index.php/estadisticas-por-tema/demografia-y-poblacion/censo-general2005-1/censo-general-2005.

COLOMBIA, Departamento Administrativo Nacional de Estadística (2012): Conciliación Censal 19852005 y Proyecciones de Población 2005-2020, www.dane.gov.co. 
COLOMBIA, Departamento Nacional de Planeación (2015): Dirección de Desarrollo Social - Dirección de Estudios Económicos (DNP-DDS-DEE - 2012), https://www.dnp.gov.co/programas/direccionde-estudios-economicos/Paginas/Direcci\%C3\%B3n-de-Estudios-Econ\% C3\%B3micos.aspx

DE LORENZO, R. \& SEMPERE, A. (Dirs.) (2016): Comentarios a las Leyes del Tercer Sector de Acción Social y del Voluntariado: Volumen I, Aranzadi, Madrid.

DOYAL, L. \& GOUGH, I. (1994): Teoría de las necesidades humanas, Icaria Editorial, Barcelona.

EQUIPO PORTAL MAYORES (2010): "Estadísticas sobre residencias: distribución de centros y plazas residenciales por provincia. Datos de octubre de 2010", Informes Portal de Mayores, 104, 19.

ESPINOSA, E. \& LIBREROS, M. (1995): Modelo básico para el mejoramiento de la calidad de vida del viejo recluso durante su permanencia en la cárcel del distrito judicial de Cali, Tesis de grado, Universidad de San Buenaventura, Santiago de Cali.

FERNÁNDEZ-BALLESTEROS, R. \& MACIÁ, A. (1993): "Calidad de vida en la vejez", Intervención Psicosocial, 11(5): 77-94.

FERNÁNDEZ-BALLESTEROS, R. (2000): Gerontología social, Pirámide, España.

GARRIGA, E. \& MELE, D. (2004): "Corporate Social Responsibility Theories: Mapping the Territory", Journal of Business Ethics, 53 (1): 51-71

HERNÁNDEZ-ASCANIO, J., TIRADO, P. \& ARIZA-MONTES, A. (2016): "El concepto de innovación social: ámbitos, definiciones y alcances teóricos", CIRIEC-España, Revista de Economía Social, Pública y Cooperativa, 88, 165-199.

HUENCHUAN, S. (2004): Marco legal y de políticas a favor de las personas mayores en América Latina, serie Población y desarrollo, 51. CEPAL. Publicación de las Naciones Unidas. Working Paper No. (LC/L.2115-P), http://repositorio.cepal.org/handle/11362/7193.

HUENCHUAN, S. (2010): Envejecimiento y derechos humanos: situación y perspectivas de protección. Comisión Económica para América Latina y el Caribe-CEPAL

http://repositorio.cepal.org/bitstream/handle/11362/3803/lcw353es.pdf?sequence=1\&isAllowed=y

IMSERSO (2014): Estadísticas del SAAD. En: Portal de la Dependencia, http://www.dependencia.imserso.es/dependencia_01/documentacion/estadisticas/index.htm

JORGE, J., ALBARRÁN, C. \& SALINAS, F. (2013): "La Economía Social ante el nuevo paradigma de Bienestar social", CIRIEC-España, Revista de Economía Pública, Social y Cooperativa, 79, 534.

MARTÍNEZ, I. (Dir.) (2011): El impacto socioeconómico de las entidades de Economía Social. Identificación, medición y valoración de los efectos vinculados a los principios de actuación de las empresas de la Economía Social, Confederación Empresarial Española de la Economía Social (CEPES), Madrid. 
MERINO, S. (2016): "Posibilidades del Cooperativismo en el nuevo modelo de servicios públicos socio sanitarios y su concreción en el País Vasco", CIRIEC-España, Revista de Economía Social, Pública y Cooperativa, 87, 139-176.

MINISTERIO DE SALUD Y PROTECCIÓN SOCIAL (2013): Envejecimiento demográfico, Colombia 1951-2020, Dinámica demográfica y estructuras poblacionales, D.C., Colombia, Bogotá.

MIQUEL, A.B. (2015): "La medición del bienestar económico a través de las macromagnitudes de la contabilidad nacional", CIRIEC-España, Revista de Economía Pública, Social y Cooperativa, 85, 245-286.

MUÑOZ, N. (2015): "Estrategias de sostenibilidad, responsabilidad social e innovación en el plan de negocio de la PYMES", CIRIEC-España, Revista de Economía Pública, Social y Cooperativas, 85, 83-108.

ORGANIZACIÓN DE LAS NACIONES UNIDAS (2017): "Envejecimiento". En: Informe Perspectivas de la población mundial. Comisión de Desarrollo Social, Plan de Acción Internacional sobre el Envejecimiento, http://www.un.org/es/sections/issues-depth/ageing/index.html.

ORGANIZACIÓN MUNDIAL DE SALUD (2014): Documentos básicos de la OMS-OPS, Documento Oficial, $48^{\mathrm{a}}$ Edición, http://apps.who.int/gb/bd/s/s_index.html.

OSORIO, L. (2010): "Gestión para el desarrollo productivo empresarial municipal", Revista Sociedad y Utopia, 35: 33-54, http://www.sociedadyutopia.es/images/revistas/35/35.pdf.

OSORIO, L. \& SALINAS, F. (2016): "El contexto y el centro residencial para las personas adultos mayores en Colombia y España. La empresa social una alternativa para el bienestar", REVESCO, Revista de Estudios Cooperativos, 121, doi:10.5209/rev_reve.2016.v121.51307

OSORIO, L. \& SALINAS, F. (2012): Las residencias y otros alojamientos para las personas mayores: tendiendo puentes entre España e Iberoamérica. El papel de la Economía Social, Ponencia en el VII Congreso Internacional Rulescoop 2012, Valencia, 5-7 de septiembre.

OSORIO, L., SALINAS, F., BELTRAN, Á. \& PALMA, M. (2017): Variables de Influencia en la Preferencia y Lealtad de Marca, en Residencias de Adultos Mayores. Un Análisis Social Comparativo entre Ávila-Madrid (España) y Santiago de Cali (Colombia), Informe de la investigación, 350 pp.

PINO, E. \& SÁENZ-RICO, M.B. (2014): "La dimensión social de la universidad del siglo XXI: creación del programa de aprendizaje-servicio en la Universidad Técnica de Ambato", Revista Iberoamericana de Educación, 65(1): 1-11, https://rieoei.org/RIE/article/view/334.

RODRÍGUEZ, G. \& MARBÁN, V. (2015): Análisis prospectivo sobre los retos actuales y futuros del Tercer Sector de Acción Social. Parte l: El Tercer Sector de Acción Social en el contexto de la Unión Europea. Situación actual y tendencias de futuro del TSAS en España, Plataforma de ONG de Acción Social, Madrid. 
RODRÍGUEZ, A., MOYANO, J. \& JIMÉNEZ, J.J. (2015): "Estado actual de la investigación en Responsabilidad Social Corporativa a nivel organizativo: consensos y desarrollos futuros", CIRIECEspaña, Revista de Economía Pública, Social y Cooperativa, 85, 143-179.

SAJARDO, A. \& RIBAS, Ma .A. (2014): "La inversión Social de las empresas: el voluntariado corporativo en España", CIRIEC-España, Revista de Economía Pública, Social y Cooperativa, 80, 161181.

SALCEDO, J.L. (2014): Una Perspectiva de la Realidad Social y el Actual Panorama de las Políticas Gubernamentales y Sociales de la Población de la Tercera Edad en Colombia, Tesis de Grado, Cali: Universidad Autónoma de Occidente, Cali, 92 pp.

SALINAS, F., CHIVITE, Ma.P. \& MUÑOZ, N. (2016): Responsabilidad Social, Administración Pública y Buen Gobierno, 87, 5-10.

SALINAS, F., OSORIO, L. \& ALBARRÁN, C. (2011): "El sector público y la Economía Social en la atención a la dependencia", CIRIEC-España, Revista de Economía Pública, Social y Cooperativa, 71, 9-24.

SANTOS, M. \& VALENCIA, N. (2015): "Envejecer en Colombia". En: América Latina Hoy, 71: 61-81.

VERA, M. (2007): "Significado de la calidad de vida del adulto mayor para sí mismo y para su familia", Revista Anales de la Facultad de Medicina, 68: 284-290.

http://www.scielo.org.pe/pdf/afm/v68n3/a12v68n3.pdf. 